\section{Psychosocial Pathways to STEM Engagement among Graduate Students in the Life Sciences}

\author{
Sheri L. Clark, ${ }^{\text {* }}$ Christina Dyar, ${ }^{\ddagger}$ Nina Maung, ${ }^{\dagger}$ and Bonita London ${ }^{*}$ \\ ${ }^{\dagger}$ Center for Inclusive Education and "Department of Psychology, Stony Brook University, \\ Stony Brook, NY 11794
}

\begin{abstract}
Despite growing diversity among life sciences professionals, members of historically underrepresented groups (e.g., women) continue to encounter barriers to academic and career advancement, such as subtle messages and stereotypes that signal low value for women, and fewer opportunities for quality mentoring relationships. These barriers reinforce the stereotype that women's gender is incompatible with their science, technology, engineering, and mathematics (STEM) field, and can interfere with their sense of belonging and self-efficacy within STEM. The present work expands this literature in two ways, by 1) focusing on a distinct period in women's careers that has been relatively understudied, but represents a critical period when career decisions are made, that is, graduate school; and 2) highlighting the buffering effect of one critical mechanism against barriers to STEM persistence, that is, perceived support from advisors. Results of the present study show that perceived support from one's advisor may promote STEM engagement among women by predicting greater gender-STEM identity compatibility, which in turn predicts greater STEM importance among women (but not men). STEM importance further predicts higher sense of belonging in STEM for both men and women and increased STEM self-efficacy for women. Finally, we describe the implications of this work for educational policy.
\end{abstract}

\section{INTRODUCTION}

Despite recent gains in degrees awarded to women in the life sciences, women are less likely to hold tenure-track faculty positions in this area and are more likely to leave the life sciences academic research workforce than men (Nelson, 2007; National Institutes of Health [NIH], 2012; National Science Foundation, National Center for Science and Engineering Statistics, 2013; Sheltzer and Smith, 2014). For example, in the top 50 biological science departments, women comprised only $25 \%$ of tenured or tenure-track faculty positions and less than $18 \%$ of full professors (Nelson, 2007). Recently, psychosocial research has been leveraged to help identify the mechanisms by which these inequalities persist (e.g., Shaw and Barbuti, 2010; Block et al., 2011). While most structural or formal barriers to the inclusion of women in science, technology, engineering, and mathematics (STEM) fields have been removed (e.g., exclusion of women from higher education), psychosocial, implicit, and often informal barriers remain and may continue to undermine women's full inclusion and participation in certain domains (e.g., Hill et al., 2010; Moss-Racusin et al., 2012; Leslie et al., 2015).

This paper will examine the critical importance of psychosocial factors present in the STEM environment that can promote investment and engagement in STEM fields. As in our previous work, we define STEM engagement as "the academic and social variables that are essential not only for retention but also for sustained investment and satisfaction in STEM fields" (London et al., 2011, p. 305). Research in psychology and education has compellingly documented many psychosocial variables and contextual factors that can critically undermine women's engagement in
Kenneth Gibbs Monitoring Editor Submitted January 16, 2016; Revised June 16, 2016; Accepted June 16, 2016

CBE Life Sci Educ September 1, 2016 15:ar45 DOI:10.1187/cbe.16-01-0036

*Address correspondence to: Sheri L. Clark (sheri .clark@stonybrook.edu).

(c) 2016 S. L. Clark et al. CBE-Life Sciences Education @ 2016 The American Society for Cell Biology. This article is distributed by The American Society for Cell Biology under license from the author(s). It is available to the public under an Attribution-Noncommercial-Share Alike 3.0 Unported Creative Commons License (http://creativecommons.org/licenses/ by-nc-sa/3.0).

"ASCB®" and "The American Society for Cell Biology $\circledR^{\prime}$ are registered trademarks of The American Society for Cell Biology. 
STEM fields. For example, Brainard and Carlin (1998) highlight the chilly and sometimes hostile environment reported by undergraduate women in STEM, which ultimately compromises their sense of fit and belonging in STEM domains. Specifically, women often report unapproachable faculty, poor advising, and feeling intimidated in STEM domains (Brainard and Carlin, 1998). Further, given that women hold so few senior-level faculty positions in the life sciences (Nelson, 2007) and encounter negative expectations and stereotypes from peers and faculty (Steele et al., 2002; Moss-Racusin et al., 2012), it is not surprising that they often report fewer opportunities for mentoring compared with their male peers (e.g., Noe, 1988; Smith et al., 2000). Even when mentoring relationships are present, the quality of those relationships may be lower for female STEM students compared with their male peers (Brainard and Carlin, 1998).

Taken together, these subtle threats to women's inclusion in STEM domains can interfere with their overall engagement in STEM fields. The threats they encounter undermine the extent to which they value these disciplines and develop a sense of belonging and academic confidence and efficacy within these domains. Importantly, much of the research into these psychosocial pathways to STEM engagement has typically focused on STEM students in grades K-12 and at the undergraduate college level (e.g., Brainard and Carlin, 1998; Lent et al., 2005; Larose et al., 2006; Marra et al., 2009; London et al., 2011; Good et al., 2012). Furthermore, research has also primarily focused on identifying barriers to STEM engagement. Yet highlighting the pathways that promote STEM engagement among women is just as critical to understanding women's underrepresentation in STEM. In this study, we focus on life sciences scholars during a critical career time period (i.e., graduate school) and identify the psychosocial pathways that help promote and maintain STEM engagement, particularly among women. We introduce several critical components of STEM engagement in the sections that follow.

\section{Experiences of Women in STEM}

Many women report a hostile and unwelcoming environment in their STEM domains (e.g., Settles et al., 2006; Hill et al., 2010). Social science research has demonstrated that the longheld belief that women are less naturally gifted, skilled, and represented across many STEM domains remains pervasive (e.g., Steinpreis et al., 1999; Reuben et al., 2014). These beliefs can be conveyed to women either directly (e.g., when men are given preference over women in hiring decisions) or covertly (e.g., via implicit bias). Together, these negative expectations and stereotypes create a context of threat and alienation that has been shown to undermine women's sustained engagement in STEM domains (e.g., Hill et al., 2010; Lane et al., 2012). As one example of the impact of the STEM environment on women's STEM engagement, previous research has shown that, among undergraduates, perceiving that others within a STEM domain value natural ability and genius over hard work and effort may undermine women's sense of belonging within that domain (Good et al., 2012). Providing further evidence that this type of environment may be especially problematic for women, Leslie and colleagues (2015) found that, in fields in which faculty report valuing genius and natural ability over effort (the biological sciences is one such field), women are more likely to be underrepresented. This suggests that being in an environment where STEM department faculty value genius and natural ability over effort may reinforce the notion that women are not naturally gifted or talented in STEM domains. In an international study with data from more than 350,000 participants in 66 nations, Miller et al. (2015) demonstrated that implicit stereotypes of women in STEM were robust, even in regions where women had greater STEM representation. The biases and negative expectations women encounter in STEM are often perpetrated at both the peer and faculty level. For example, Moss-Racusin and colleagues (2012) showed that science faculty demonstrated implicit bias that favored men over women in evaluating STEM ability in line with gender stereotypes. Specifically, when science faculty evaluated male and female applicants for a lab manager position (applicants were identical except for the gender implied by their name), they rated the male applicant as more competent and more likely to be hired compared with a female applicant. Other work has also shown a similar gender bias in evaluating the conference abstracts submitted by male scientists, with male scientists' abstracts being rated as higher quality than identical abstracts submitted by female scientists (Knobloch-Westerwick et al., 2013). Taken together, these findings (and others) confirm the presence and persistence of gender biases and negative stereotypes of women within many STEM domains.

Negative stereotypes and negative expectations of women's abilities or belonging and fit in STEM domains impact the broader culture of STEM contexts by defining notions of who belongs, who is expected to be successful, and who is valued in a given field (e.g., Spencer et al., 1999; Appel et al., 2011; Burgess et al., 2012; Moss-Racusin et al., 2012; Woodcock et al., 2012; Knobloch-Westerwick et al., 2013; Leslie et al., 2015). The threats and negative experiences that women are likely to encounter in STEM domains may undermine women's identities as scientists, and they may begin to question their own competence in STEM and the extent to which they belong in STEM. Specifically, women may begin to notice the underrepresentation of women in their STEM fields and signs within the environment, including messages from representatives of their STEM fields (e.g., peers, professors), suggesting that women are not valued as scientists. STEM identity is critical, because it sets up additional processes by which individuals judge their competence and belonging in a domain (Settles, 2004; London et al., 2011; Rosenthal et al., 2011, 2013). While implicit biases can manifest in overt behavioral discrimination (e.g., in the case of hiring or admissions decisions that favor STEM men over STEM women), they also have implicit effects by communicating to women that they are devalued in and incompatible with the their chosen STEM fields because of their gender. Thus, a critical problem faced by many women in nontraditional fields is a sense of incompatibility between their gender and the fields they are pursuing (Shih et al., 1999; Settles, 2004; Settles et al., 2009; London et al., 2011; Rosenthal et al., 2011).

\section{STEM Identity Compatibility}

Experiencing incompatibility between one's gender and one's STEM field may undermine one's STEM engagement. For instance, social identity theory (e.g., Tajfel and Turner, 1979) posits that all individuals adopt multiple layers of personal and social identities (e.g., a woman, a mother, a doctor), and that 
those identities become a lens through which individuals view the world, the decisions they make, and the sense of connection they have to others (Tajfel and Turner, 1979). When one's identities conflict (i.e., when they are incompatible), the result may be anxiety and stress that leads an individual to try to reduce that tension or dissonance (Cooke and Rousseau, 1984; Coverman, 1989; Settles, 2004). For example, people have been shown to struggle within both academic and social environments that communicate a conflict between two or more of their identities (Tajfel and Turner, 1979; Hogg and Abrams, 1988; Roccas and Brewer, 2002; Ashmore et al., 2004). Further, in the context of STEM fields, Carli et al. (2016) and others have demonstrated there is greater perceived similarity (or compatibility) between stereotypes of men and stereotypes of scientists compared with stereotypes of women and stereotypes of scientists.

Drawing on social identity theory, London and colleagues (2011) defined and operationalized gender-STEM identity compatibility as the degree to which an individual believes his or her gender (whether male or female) overlaps with or is compatible with his or her identity as a scientist. Given foundational evidence from social identity theory, identity compatibility, then, may be a critical underlying mechanism that guides the goals individuals choose to pursue and how individuals cope with perceived conflict between goals. London and colleagues (2011) have demonstrated that perceived identity compatibility is a critical component of women's STEM engagement. Among samples of undergraduates, research has shown that gender-STEM identity compatibility for women predicts increased sense of belonging to their STEM fields and increased levels of motivation (London et al., 2011; Rosenthal et al., 2011), lower levels of academic insecurity (London et al., 2011), and a lower likelihood of considering dropping out of a STEM major (London et al., 2011). Similarly, Settles (2004) found that perceiving increased compatibility between one's identity as a woman and one's identity as a scientist is related to higher levels of well-being and performance among female undergraduate and graduate students in STEM fields. Further, Diekman et al. (2010) report that, when women perceive that a STEM career conflicts with their broader communal goals of helping others (goals that are more commonly endorsed among women), their interest in STEM is reduced (even if they experienced past success in STEM). Taken together, research has demonstrated that perceived identity compatibility among women in STEM is a critical psychosocial pathway to STEM engagement. Moreover, the social identity literature further suggests that individuals use their identities to make judgments about their competence, belonging, and future expectations (Hogg and Abrams, 1988). Thus, perceived identity compatibility may be a critical first step in women developing confidence in their academic skills and social belonging in STEM domains.

\section{Mentoring and Support}

Although a number of research studies have established that identity compatibility is an important key to STEM engagement (e.g., London et al., 2011; Rosenthal et al., 2011), little research to date has examined factors that may promote identity compatibility among STEM women. However, previous work has pointed to the importance of the mentoring relationship between faculty and students for student success and engagement (e.g., Cronan-Hillix et al., 1986; Taylor and Antony, 2000;
Rosenthal et al., 2011; NIH, 2012). For example, Cronan-Hillix and colleagues (1986) demonstrate that having a mentor is related to increased academic productivity (e.g., increased publications and conference presentations). Moreover, the quality of one's mentoring relationship has implications for academic productivity (Lovitts, 2001) and degree progress (Maher et al., 2004). Additionally, experiencing both a threatening academic environment and an unsupportive advisor may undermine one's pursuit of an academic career (Taylor and Antony, 2000). Despite the importance of supportive mentoring relationships for STEM success, research has consistently shown that women and ethnic minorities often lack opportunities to receive support and mentorship (e.g., Noe, 1988; Smith et al., 2000) and often have poorer mentoring relationships (Ferreira, 2003).

Further, in a parallel line of work, research on the presence of role models suggests that exposure to models of STEM success predicts greater engagement and investment in STEM domains, particularly among women (Stout et al., 2011; Rosenthal et al., 2013; Shin et al., 2016). Critically, for women, role models or positive mentoring in STEM may signal that their gender and their STEM career pursuits are compatible by demonstrating that women have been successful in STEM (in the case of female role models) or by providing women in STEM with the support they need to be successful (in the case of having a supportive mentor). Receiving support and guidance from a graduate advisor may either directly promote feelings of genderSTEM identity compatibility among STEM women by confirming the advisor values and supports the student, or may moderate or buffer other stereotype-relevant experiences women encounter in graduate school (e.g., perceptions of sexism; Ahlqvist et al., 2013). Accordingly, in the present study, we theorize that a supportive and helpful mentor may be critical for women in STEM. Academic advisors are respected members of the STEM community and therefore may be viewed by the student as proxies of the STEM community. Thus, perceiving one's advisor as supportive may signal that one is a valued member of the STEM community and override messages in the environment suggesting that women are not valued in STEM. Therefore, we expect that perceived support from one's academic advisor may predict higher perceptions of gender-STEM identity compatibility among women, because this perception signals to students that their gender is compatible with being a successful scientist in the STEM community. Given that men may not struggle with the same gender-STEM identity incompatibility because they are stereotyped as highly successful in STEM domains, we theorize that supportive advising will be inconsequential to men's belief in their gender-STEM identity compatibility.

\section{STEM Importance and Social and Academic Engagement}

Ultimately, the processes described above (supportive mentoring predicting increased gender-STEM identity compatibility among women in the life sciences) are theorized to impact the extent to which women view their STEM domains as important and their academic and social engagement within their STEM domains. Research indicates that individuals whose abilities are subjected to negative stereotypes in a domain may protect themselves against this threat by deidentifying with or disengaging from that domain (e.g., Osborne, 1997; Osborne and Walker, 2006; Major et al., 1998; Steele et al., 2002; Smith et al., 2007), so we expect that women who do not have 
supportive advisors to buffer them against the threatening context of the STEM environment are more likely to disengage from their STEM domains and discount the value of their STEM domains.

STEM Importance. Eccles's (1994) expectancy value theory of achievement motivation and Lent, Brown, and Hackett's (1994) social cognitive theory of career development both suggest that one critical component to both persistence in STEM and academic and social engagement in STEM is whether one values a particular domain or views a particular domain as important (Eccles, 1994; Wigfield and Eccles, 1992, 2000; Lent et al., 1994). Perceiving a domain to be important is a key factor in guiding career choices and decisions (Eccles, 1994; Lent et al., 1994), motivation (Eccles and Wigfield, 2002), and persistence, even when facing difficulty (Wigfield and Eccles 1992), and ultimately may promote sustained engagement in a given domain. The perceived importance of a domain to an individual predicts higher likelihood of persisting in that domain (Wigfield and Eccles, 1992), which may be expressed by engaging in more domain-specific activities (e.g., enrolling in classes or learning new domain-specific skills). Importantly, each time an individual engages in a domain-specific task (e.g., taking a course, attempting to perform a new skill), this provides an opportunity for the individual to have experiences mastering a domain-specific task (i.e., mastery experience). Mastery experiences have been shown to increase one's confidence or self-efficacy in a domain (Bandura, 1977, 1997). Therefore, we expect that lower STEM importance will predict lower STEM self-efficacy. Similarly, we expect that STEM importance is related to sense of belonging in STEM. Specifically, we predict that because individuals are more likely to spend time and effort on valued activities, individuals who believe that their STEM fields are important will be more likely to spend increased amounts of time engaging in STEM activities within their STEM domains and therefore have more opportunities to develop supportive relationships with others in their STEM domains. Previous work has shown that supportive relationships help to foster an increased sense of belonging in STEM (Rosenthal et al., 2011). Accordingly, we expect that higher levels of STEM importance will be related to both higher levels of STEM self-efficacy as well as sense of belonging in STEM.

STEM Self-Efficacy. Self-efficacy refers to one's belief or confidence in one's ability to successfully complete a task or be successful in a specific domain (Eccles, 1994; Lent et al., 1994; Bandura, 1997; Pajares, 2005; Diekman et al., 2010). Self-efficacy has been shown to predict student motivation and task performance (e.g., Bandura and Locke, 2003; Caprara et al., 2011), task and career confidence (e.g., Pajares, 2005), goals and persistence (e.g., Eccles, 1994; Lent et al., 1994), and vocational choices (e.g., Larose et al., 2006). Additionally, higher self-efficacy in a given domain is related to higher persistence in that domain (Adedokun et al., 2013). Consistent with our theorizing, previous work has shown that women in STEM have lower levels of efficacy compared with men (e.g., Mura, 1987; Strenta et al., 1994). Moreover, Larose and colleagues (2006) report that self-efficacy may be a stronger predictor of vocational choices for women. Of particular importance to the present work, research has shown that women with higher levels of self-efficacy have an increased likelihood of intending to persist in a STEM field (Marra et al., 2009). Given the link between self-efficacy and persistence in STEM, understanding the factors that predict self-efficacy is important for understanding how to increase persistence among women in STEM. On the basis of the results of previous work showing that self-efficacy is a stronger predictor of STEM persistence among women (Larose et al., 2006), we expect that STEM importance may be especially critical for women's relative to men's STEM self-efficacy.

STEM Sense of Belonging. While previous research compellingly demonstrates that confidence in one's academic STEM skills is critical for many STEM success outcomes, social engagement (i.e., sense of belonging) has also been shown to predict STEM success. Therefore, it is important to understand the factors that may foster a sense of belonging among women in STEM to better understand how to promote STEM success among women. London and colleagues (2011) define sense of belonging as the level of comfort, connection, and welcome an individual feels within a domain. Similarly, Good et al. (2012) identify sense of belonging as one's feelings of membership or acceptance in a particular domain. Sense of belonging has been shown to be important for career interest (Rosenthal et al., 2013), academic achievement (Walton and Cohen, 2007), motivation (Smith et al., 2013), and performance in and intent to pursue STEM fields (Good et al., 2012). Importantly, having a low sense of belonging in one's STEM field has also been shown to undermine persistence in STEM (London et al., 2011; Good et al., 2012). Given this link between sense of belonging and persistence in STEM, it is important to examine potential predictors of sense of belonging in order to develop policies and practices that support persistence in STEM. Furthermore, previous research has documented gender differences in sense of belonging in STEM fields, with women reporting a lower sense of belonging than men (Good et al., 2012). Accordingly, we expect that STEM importance may be especially crucial for women's sense of belonging in STEM fields.

Taken together, these processes of perceived STEM importance and academic (efficacy) and social (belonging) engagement in STEM may be key contributors to persisting in STEM. We theorize that students' greater gender-STEM identity compatibility will predict higher perceived importance of one's STEM field and that importance will predict greater academic (i.e., self-efficacy) and social (i.e., belonging) outcomes, primarily among women. Women are more likely to encounter a threatening STEM environment compared with their male peers, and we therefore expect that higher levels of STEM importance will predict higher levels of both self-efficacy and belonging in STEM for women.

\section{Graduate Students in Life Sciences}

Most of the aforementioned studies demonstrate the importance of gender-STEM identity compatibility among students in $\mathrm{K}-12$ and undergraduate college students. $\mathrm{K}-12$ and college undergraduates are at the very beginning of their potential STEM career trajectories and may not have established lasting investment in a STEM career or aspire to work toward a graduate degree or faculty position in their STEM fields. For instance, fewer than half of bachelor's degree recipients attend graduate school (Mattern and Redunzel, 2015), and only 15\% 
of bachelor's degree recipients in biological, environmental, and agricultural sciences were employed in STEM as recently as 2012 (U.S. Census Bureau, 2014). Although some previous work has focused on the graduate school experience for members of historically underrepresented groups in STEM (e.g., Nyquist et al., 1999; Taylor and Antony, 2000; Ellis, 2001; Settles, 2004; Carlone and Johnson, 2007; Gardner, 2008; Gopaul, 2011; Gibbs and Griffin, 2013; Gibbs et al., 2014), relatively few quantitative studies have focused on this critical period in one's STEM career. Graduate STEM students, by virtue of being admitted to and enrolling in a competitive doctoral program, have already demonstrated some level of interest, commitment, and skill within STEM disciplines. Yet they remain a vulnerable population to the persistent STEM stereotypes and identity incompatibility prevalent in STEM domains. Moreover, an evaluative setting (i.e., a setting in which one's abilities are frequently tested and scrutinized) may make stereotypes and identity incompatibility become more salient among members of these vulnerable populations, leading to anxiety about appearing competent and undermining performance (e.g., Steele, 1997). The research environment (i.e., the $\mathrm{PhD}$ experience) is an example of a high-stakes evaluative setting that may trigger anxiety among students to appear competent and therefore may chronically undermine the performance of stigmatized students (e.g., women, minorities). Further, graduate school is a context in which scholars are more often mentored in one-on-one relationships with faculty advisors. Those advisors provide not only academic guidance and training but are also responsible for the career trajectory of the student and the lab culture that conveys messages of value, belonging, respect, and so on. Graduate scholars may be a critical group in which to extend the study of mechanisms of engagement in STEM, and graduate school is an important context for studying the impact of STEM mentoring.

Finally, the present work provides valuable insights for how to broaden participation in the life sciences by suggesting specific programmatic interventions designed to help students overcome barriers to persistence and engagement in the life sciences identified in the present research.

\section{METHOD}

\section{Procedure}

Data for this study were collected in the context of a larger, longitudinal study of graduate students in STEM fields. Students enrolled in STEM doctoral programs at a research-intensive university were recruited to participate in the online student survey. The broader longitudinal study was funded by the National Science Foundation (HRD-1311318) and included inclusion/exclusion criteria that all participants should be U.S. citizens and currently enrolled as full-time students in STEM disciplines. The response rate for this study was 52\%. Participants completed surveys before the start of the Fall semester. Participants were paid $\$ 20$ for participating in the survey and were additionally entered into a raffle to win a $\$ 100$ prize.

\section{Participants}

Three hundred thirty-two doctoral students in social science and STEM programs completed the online survey. Two hundred and five of those students were enrolled in doctoral programs in STEM, and 102 of those students were enrolled in doctoral programs in the biological sciences. However, 29 participants were missing data on multiple variables of interest and were therefore excluded from these analyses. Participants were required to be U.S. citizens. Demographic information for the 73 students included in these analyses is reported. The mean age of the sample was 25.9 years ( $S D=3.6) ; 49.3 \%$ of our sample was female. The majority of our sample was Caucasian/ white $(69.9 \%$ ), with $12.3 \%$ Hispanic or Latino/a, $4.1 \%$ East Asian, 4.1\% South Asian, 6.8\% African American/Caribbean American/black, $1.4 \%$ American Indian/Native Alaskan, and $1.4 \%$ multiracial or other. The racial/ethnic distribution of male and female subsamples were similar $\left(\chi^{2}(6)=3.45\right.$, $p=0.75$ ), with $75.7 \%$ of men and $63.9 \%$ of women being Caucasian/white, $10.8 \%$ of men and $13.9 \%$ of women being Hispanic or Latino/a, 2.7\% of men and 5.6\% of women being East Asian, $2.7 \%$ of men and $5.6 \%$ of women being South Asian, $8.1 \%$ of men and $5.6 \%$ of women being African American/ Caribbean American/black, $0.0 \%$ of men and $2.8 \%$ of women being American Indian/Native Alaskan, and $0.0 \%$ of men and $2.8 \%$ of women identifying as multiracial or other. The sample was cross-sectional, with approximately one-quarter of our sample in their first year in their current graduate programs (26.1\%), 23.3\% in their second year, $13.7 \%$ in their third year, $15.1 \%$ in their fourth year, and $21.8 \%$ in their fifth year or later. Of our sample, $52.1 \%$ indicated their advisors had tenure.

\section{Measures}

Perceived advisor supportiveness was measured using three items ( $\alpha=0.81$ ) developed for this study (see the Supplemental Materials for full measure). Items assessed the extent to which participants viewed their academic advisors as being helpful and supportive and that they met with their advisors regularly (e.g., "[My academic advisor] is supportive"). Items were assessed using a scale of 1 (strongly disagree) to 7 (strongly agree).

Gender-STEM identity compatibility was measured using an adapted version of the Inclusion of Other in Self measure (Aron et al., 1992; Tropp and Wright, 2001). The single item of this measure was adapted to measure the perceived compatibility between one's gender and one's STEM field (London et al., 2011). A pictorial scale of increasingly overlapping circles is used to indicate the extent to which a participant perceives an overlap or compatibility between his/her gender and STEM field; 1 indicated the least amount of compatibility and 7 the highest amount of compatibility.

STEM importance (adapted from Luhtanen and Crocker, 1992; London et al., 2011) was measured using three items ( $\alpha=0.90$ ). Items assessed the extent to which participants felt that being in a STEM field was important (e.g., "Overall, my membership in the STEM community is important to me"). Items were assessed on a scale of 1 (strongly disagree) to 6 (strongly agree).

Domain-specific self-efficacy was measured via a 25 -item scale $(\alpha=0.93$ ) developed for this study (see the Supplemental Materials for full measure). Items assessed the extent to which participants felt confident in their abilities to complete a variety of tasks necessary for success in a STEM graduate program (e.g., "writing a paper for publication," "giving a successful job interview," and "presenting research results to an audience of peers") on a scale ranging from 1 (no confidence) to 5 (absolute confidence). 
TABLE 1. Correlations among major study variables

\begin{tabular}{|c|c|c|c|c|c|c|c|c|}
\hline Variable & 1 & 2 & 3 & 4 & 5 & 6 & 7 & 8 \\
\hline 1. Year in program & - & 0.09 & 0.11 & -0.13 & 0.10 & -0.14 & -0.07 & $-0.26^{*}$ \\
\hline 2. URM status & & - & 0.07 & -0.22 & -0.11 & $0.29 *$ & 0.17 & 0.07 \\
\hline 3. Gender & & & - & -0.21 & -0.02 & 0.04 & -0.01 & 0.03 \\
\hline 5. Gender-STEM compatibility & & & & & - & $0.25^{*}$ & 0.06 & 0.14 \\
\hline 6. STEM Importance & & & & & & - & $0.28 *$ & $0.43 *$ \\
\hline 7. Self-efficacy & & & & & & & - & 0.22 \\
\hline $\mathrm{M}$ & 2.94 & - & - & 5.76 & 4.82 & 4.70 & 3.78 & 8.33 \\
\hline SD & 1.73 & - & - & 1.11 & 2.15 & 0.99 & 0.55 & 1.38 \\
\hline
\end{tabular}

$* p<0.05$.

$* * p<0.001$

Belonging in field (Mendoza-Denton et al., 2002) was measured using six items $(\alpha=0.92)$ and was adapted from the measure of belonging in university developed by Mendoza-Denton and colleagues (2002). The instructions were altered to ask participants to select the number that best describes their feelings toward their fields of study for four items: 1 (miserable to be there) to 10 (thrilled to be there), 1 (do not fit in) to 10 (definitely fit in), 1 (not welcome) to 10 (very welcome), and 1 (very uncomfortable) to 10 (very comfortable); and to select the number that best describes their feelings toward their peers and classmates in their fields for two items: 1 (do not like them) to 10 (like them) and 1 (do not feel comfortable with them) to 10 (feel very comfortable with them). To determine sense of belonging in their fields of study, we averaged responses to all six items.

\section{RESULTS}

Less than $5 \%$ of data were missing. One participant did not provide data for the compatibility between STEM field and gender and was therefore not included in the analyses using this variable. Eighteen additional participants indicated that they did not have an academic advisor for the semester in question and therefore were excluded from analyses including the perceived supportiveness of advisor variable. All other data were present. Correlations, means, and SDs for study variables are presented in Table 1.

Moderation analyses were conducted using SPSS, and simple slopes analyses were conducted using the Process macro for SPSS (Hayes, 2012). Before moderation analyses were conducted, continuous predictors to be included in the moderation analyses were mean centered to reduce nonessential multicollinearity; these centered variables were used throughout. Underrepresented minority (URM) status (non-URM ethnic/ racial identity coded as 0 , URM ethnic/racial identity coded as $1)$ and year in program were controlled for in all analyses. Betas $(\beta)$ and significances for each moderation analysis are displayed in Table $2 .^{1}$

${ }^{1}$ To test the ordering of the effects in the moderations, we conducted a set of three additional moderations in which the predictors and outcomes were reversed, including models in which: STEM importance interacts with gender to predict STEM-gender compatibility, sense of belonging in field interacts with gender to predict STEM importance, and self-efficacy interacts with gender to predict STEM importance. None of these reversed interaction models was significant ( $p=0.09$, 0.12 , and 0.66 , respectively).
In the first moderation analysis, perceived advisor supportiveness was the predictor, gender (male coded as 0 , female coded as 1) was the moderator, and perceived gender-STEM compatibility was the outcome. Neither the main effects of gender nor advisor supportiveness was significant. However, the interaction between advisor supportiveness and gender was significant. Simple slopes analyses indicated that the relationship between advisor supportiveness and perceived genderSTEM compatibility was positive and significant for women $(b=0.55, \mathrm{SE}=0.28, t(48)=2.94, p=0.05)$, but not for men $(b=-0.82, \mathrm{SE}=0.62, t(48)=-1.33, p=0.19)$. Therefore, higher perceptions of advisor supportiveness predicted higher

TABLE 2. Moderation by gender

\begin{tabular}{|c|c|c|c|c|}
\hline $\begin{array}{l}\text { Dependent } \\
\text { variable }\end{array}$ & $\begin{array}{l}\text { Independent } \\
\text { variable }\end{array}$ & $\beta$ & $t$ & $p$ \\
\hline \multirow{5}{*}{$\begin{array}{l}\text { Gender-STEM } \\
\text { compatibility }\end{array}$} & Year in program & 0.05 & 0.37 & 0.713 \\
\hline & URM status & -0.18 & -1.32 & 0.193 \\
\hline & Gender & -0.08 & -0.54 & 0.592 \\
\hline & $\begin{array}{l}\text { Advisor } \\
\quad \text { supportiveness }\end{array}$ & -0.44 & -1.33 & 0.190 \\
\hline & Interaction & $0.66^{*}$ & 2.05 & 0.046 \\
\hline \multirow[t]{5}{*}{ STEM importance } & Year in program & -0.19 & -1.78 & 0.079 \\
\hline & URM status & $0.36 * *$ & 3.39 & 0.001 \\
\hline & Gender & 0.03 & 0.32 & 0.748 \\
\hline & $\begin{array}{l}\text { Gender-STEM } \\
\text { compatibility }\end{array}$ & 0.09 & 0.71 & 0.483 \\
\hline & Interaction & $0.35^{*}$ & 2.65 & 0.010 \\
\hline \multirow[t]{5}{*}{ Self-efficacy } & Year in program & -0.05 & -0.40 & 0.689 \\
\hline & URM status & 0.09 & 0.75 & 0.455 \\
\hline & Gender & -0.03 & -0.29 & 0.776 \\
\hline & STEM importance & -0.02 & -0.10 & 0.919 \\
\hline & Interaction & $0.36^{*}$ & 2.05 & 0.045 \\
\hline \multirow{5}{*}{$\begin{array}{l}\text { Sense of belonging } \\
\text { in field }\end{array}$} & Year in program & -0.21 & -1.86 & 0.067 \\
\hline & URM status & -0.03 & -0.23 & 0.818 \\
\hline & Gender & 0.03 & 0.31 & 0.759 \\
\hline & STEM importance & $0.40^{*}$ & 2.39 & 0.020 \\
\hline & Interaction & 0.001 & -0.01 & 0.996 \\
\hline
\end{tabular}

$* p<0.05$.

$* * p<0.01$. 


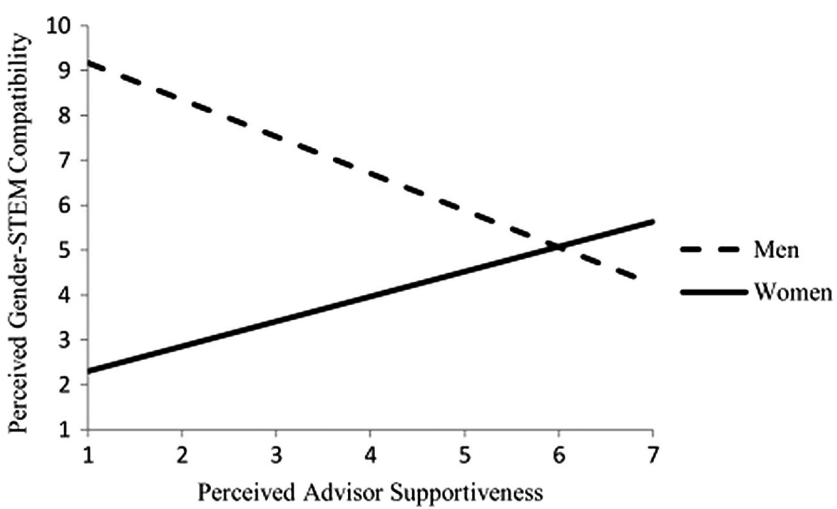

FIGURE 1. Simple slopes for the interaction between gender and perceived advisor supportiveness predicting perceived genderSTEM compatibility. Advisor supportiveness predicted increased perceived gender-STEM compatibility for women $(b=0.55, \mathrm{SE}=$ $0.28, t(48)=2.94, p=0.05)$ but not for men $(b=-0.82, \mathrm{SE}=0.62$, $t(48)=-1.33, p=0.19)$.

perceived compatibility between women's gender and STEM field, but this relationship is not significant for men. Figure 1 depicts the simple slopes for this interaction.

In the second moderation analysis, perceived gender-STEM compatibility was the predictor, gender (male coded as 0 , female coded as 1) was the moderator, and STEM importance was the outcome. The main effects of gender and gender-STEM compatibility were not significant. However, the interaction between gender-STEM compatibility and gender was significant. Simple slopes analyses indicated that higher gender-STEM compatibility predicted higher STEM importance for women $(b=0.31$, $\mathrm{SE}=0.08, t(66)=3.85, p<0.001)$, but not for men $(b=0.04$, $\mathrm{SE}=0.06, t(66)=0.70, p=0.48)$. Figure 2 depicts the simple slopes for this interaction.

In the third moderation analysis, STEM importance was the predictor, gender (male coded as 0 , female coded as 1 ) was the moderator, and domain-specific self-efficacy was the outcome.

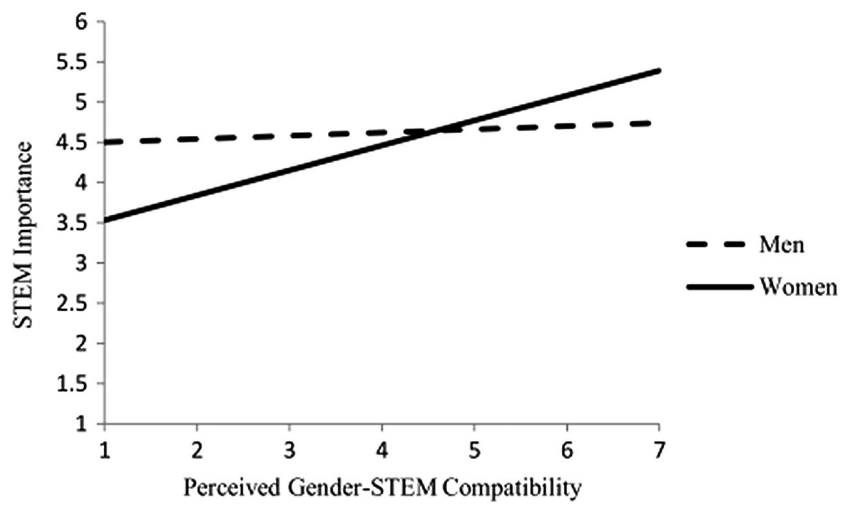

FIGURE 2. Simple slopes for the interaction between gender and perceived gender-STEM compatibility predicting STEM importance. Higher perceived gender-STEM compatibility predicted higher STEM importance for women $(b=0.31, \mathrm{SE}=0.08, t(66)=$ $3.85, p<0.001)$ but not for men $(b=0.04, \mathrm{SE}=0.06, t(66)=0.70$, $p=0.48)$

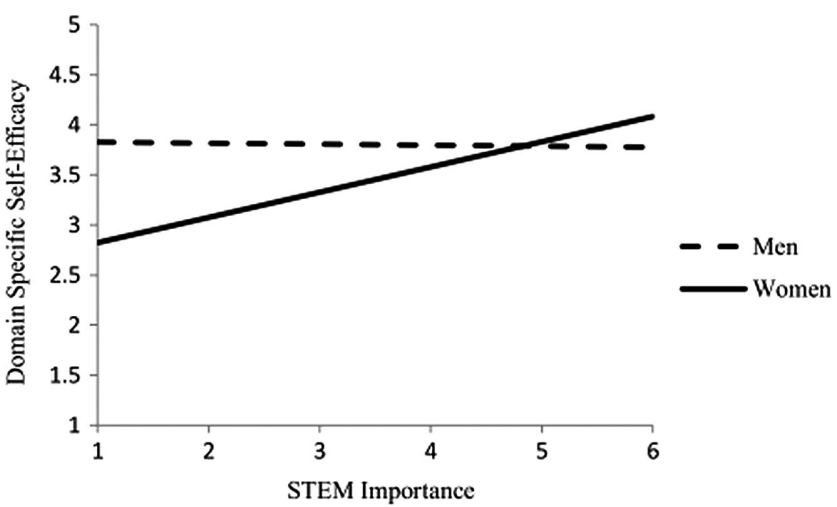

FIGURE 3. Simple slopes for the interaction between gender and STEM importance predicting domain-specific self-efficacy. Higher STEM importance predicted higher domain-specific self-efficacy for women $(b=0.25, \mathrm{SE}=0.09, t(67)=2.91, p<0.01)$ but not for men $(b=-0.01, \mathrm{SE}=0.10, t(67)=-0.10, p=0.92)$.

Neither the main effects of gender nor STEM importance were significant. However, the interaction between STEM importance and gender was significant. Simple slopes analyses indicated that higher STEM importance predicted higher domain-specific self-efficacy for women $(b=0.25, \mathrm{SE}=0.09$, $t(67)=2.91, p<0.01)$, but not for men $(b=-0.01, \mathrm{SE}=0.10$, $t(67)=-0.10, p=0.92)$. Figure 3 depicts the simple slopes for this interaction.

In the final moderation analysis, STEM importance was the predictor, gender (male coded as 0 , female coded as 1 ) was the moderator, and sense of belonging in one's field was the outcome. The interaction between STEM importance and gender was not significant, nor was the main effect of gender (see Figure 4 for simple slopes). However, the main effect of STEM importance was positive and significant. This indicates that higher STEM importance predicted higher sense of belonging in one's field for both men and women.

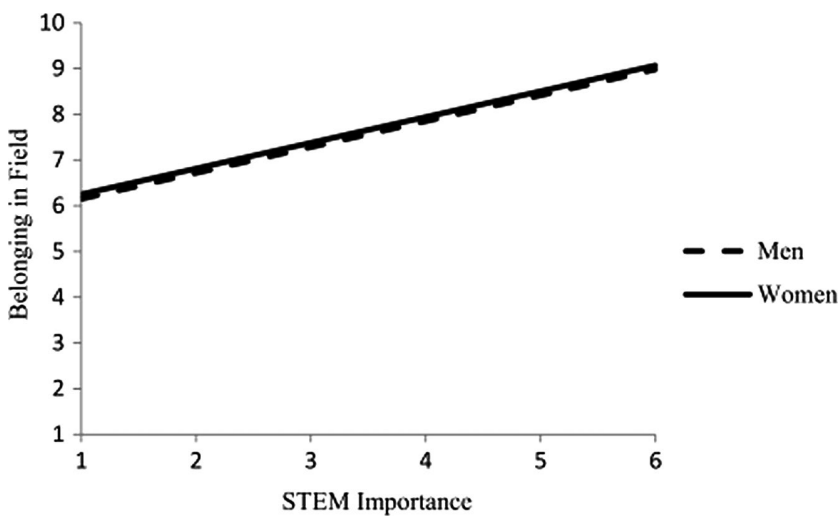

FIGURE 4. Simple slopes for the interaction between gender and STEM importance predicting sense of belonging in field. Higher STEM importance predicted higher sense of belonging in field equally for women $(b=0.56, \mathrm{SE}=0.21, t(67)=2.73, p=0.008)$ and men $(b=0.57, \mathrm{SE}=0.24, t(67)=2.39, p=0.02)$. 


\section{DISCUSSION}

Building on existing literature from psychology and education that highlights the importance of mentoring relationship quality for student engagement in STEM, the results of the current study show that perceptions of advisor supportiveness predicted higher levels of gender-STEM identity compatibility for women but not men. Higher gender-STEM identity compatibility predicted greater endorsement of STEM importance for women but not for men; and higher STEM importance, in turn, predicted greater STEM self-efficacy for women, but not for men. Finally, STEM importance predicted greater sense of belonging in one's field for both men and women.

Our findings provide support for the importance of these psychosocial constructs in promoting STEM engagement and highlight several critical issues. First, advisor support is a critical source of protection that may lead women in the life sciences to perceive greater compatibility between their gender and their STEM domains. However, advisor support is not predictive of gender-STEM identity compatibility for men. This is likely because men in STEM do not contend with the same negative stereotypes and expectations that women in STEM do, and therefore their gender-STEM compatibility may not be impacted by the presence of a supportive advisor. Second, gender-STEM identity compatibility predicts higher STEM importance for women. As other work has shown that individuals are more likely to persist (even in the face of negative experiences and challenges) in domains that are personally relevant and important to them (Wigfield and Eccles, 1992), perceiving one's STEM discipline as more important is a key step in sustained engagement. As previously mentioned, importance of STEM is particularly critical for women in STEM, who face pervasive stereotypes and an unwelcoming STEM environment. Consistent with past work (Eccles, 1994; Wigfield and Eccles, 1992, 2000; Lent et al., 1994), results indicate that perceiving STEM as important predicts greater engagement-both academic engagement in the form of self-efficacy and social engagement in the form of sense of belonging. This finding highlights the notion that, for women, importance of STEM (which is motivated by greater gender-STEM identity compatibility) impacts two critical pathways to STEM engagement: higher sense of confidence in their ability to engage in domain-specific tasks, and higher sense of belonging within the domain. Finally, these findings demonstrate that psychosocial engagement processes are important for life sciences graduate students who may remain vulnerable to disengagement from their STEM domains despite having committed to advanced education.

One unexpected finding of the present work was that higher STEM importance predicted higher sense of belonging in one's field for both men and women, whereas higher STEM importance predicted higher levels of self-efficacy for women only. One possible explanation for this finding is that higher STEM importance is more intricately linked to self-efficacy than to sense of belonging. Specifically, STEM importance may only be linked to self-efficacy for women because the STEM environment is uniquely threatening to women. As previously noted, women may respond to these threats in the STEM environment (e.g., negative stereotypes about their abilities) by devaluing their STEM fields. Sense of belonging, however, may be less strongly linked with STEM importance due to sense of belong- ing's link with other factors, such as peer friendships in STEM. Accordingly, sense of belonging may be satisfied in many other ways unrelated to STEM importance or persistence. Future work is needed to examine factors predictive of sense of belonging in STEM.

Building on the findings of the present work, future work should also examine the specific behavioral outcomes associated with lower STEM engagement, such as deciding not to pursue tenure-track faculty positions or choosing faculty positions at teaching institutions rather than research-intensive institutions. Combined with emerging literature demonstrating the importance of one's personal values in career choice (e.g., Diekman et al., 2010; Gibbs and Griffin, 2013; Smith et al., 2014; Thoman et al., 2015), understanding the behavioral outcomes associated with lower STEM engagement and how these outcomes may affect career paths will help to develop a more nuanced and complete understanding of how educational policy may be developed to facilitate women's persistence in STEM careers. Additionally, future work should examine whether the present findings generalize to other underrepresented groups, such as African-American and Hispanic students. Given that the full participation of historically underrepresented groups in STEM is necessary to ensure a strong pool of STEM workers (National Academy of Sciences, National Academy of Engineering, and Institute of Medicine, 2011), understanding the experiences of members of historically underrepresented groups in their pursuit of STEM careers is essential to the development of a strong STEM workforce that will maintain the status of the United States as a global leader in STEM innovation.

One limitation of the present study is that it examined graduate students at only one university, and we are therefore unable to determine whether these results would generalize to other universities. However, the present research was conducted at a midsized public university, which is representative of many universities across the United States. Additionally, our sample was not robust enough to test whether there were any racial/ethnic differences in 1) how perceptions of advisor supportiveness relates to identity compatibility; 2) how identity compatibility relates to STEM importance; and 3) how STEM importance relates to self-efficacy and sense of belonging. Finally, the correlational nature of the present work does not allow us to draw any causal conclusions among the study variables; however, the lack of statistical significance among the interactions tested in the alternative moderation analyses (in which the predictors and outcomes were reversed) provides some support for the variable sequence presented in the manuscript. Despite these limitations, the present work had several strengths. One key strength of this work is that it focused on a critical period in women's STEM careers that has been relatively understudied (i.e., graduate school). Additionally, this work shed light on the potential buffering effect of perceived support from advisors on women's perceived identity compatibility.

The present research highlights the importance for women who are pursuing graduate degrees in the life sciences to feel that they are in a supportive environment (e.g., feeling supported by their advisors). Given the findings of the present study, which demonstrate the impact of having an advisor who is seen as supportive and helpful on gender-STEM identity compatibility and subsequent engagement, programmatic interventions that focus on strengthening the advisor-advisee 
relationship may be a critical step in reducing the likelihood of selective attrition of women from STEM fields. Moreover, given existing research showing the negative pathways that undermine gender identity compatibility among women (e.g., presence of negative expectations and stereotypes in STEM academic settings), experiences that foster identity compatibility among women scientists are greatly needed. These possibilities, in addition to existing interventions that have been shown to be effective in buffering against negative stereotypes (for a review, see Yeager and Walton, 2011), may help educators and policy makers to greatly reduce the barriers to success for women in graduate STEM programs.

\section{ACKNOWLEDGMENTS}

Research reported in this publication was supported by a grant from the National Science Foundation's Alliances for Graduate Education and the Professoriate-Transformation program (HRD-1311318).

\section{REFERENCES}

Adedokun OA, Bessenbacher AB, Parker LC, Kirkham LL, Burgess WD (2013). Research skills and STEM undergraduate research students' aspirations for research careers: mediating effects of research self-efficacy. J Res Sci Teach 50, 940-951.

Ahlqvist S, London B, Rosenthal L (2013). How gender rejection sensitivity undermines the success of women in science, technology, engineering, and mathematics fields. Psychol Sci 24, 1644-1652.

Appel M, Kronberger N, Aronson J (2011). Stereotype threat impairs ability building: effects on test preparation among women in science and technology. Eur J Soc Psychol 41, 904-913.

Aron A, Aron EN, Smollan D (1992). Inclusion of other in the self scale and the structure of interpersonal closeness. J Pers Soc Psychol 63, 596.

Ashmore RD, Deaux K, McLaughlin-Volpe T (2004). An organizing framework for collective identity: articulation and significance of multidimensionality. Psychol Bull 130, 80

Bandura A (1977). Self-efficacy: toward a unifying theory of behavioral change. Psychol Rev 84, 191.

Bandura A (1997). Self-Efficacy: The Exercise of Control, New York: Freeman.

Bandura A, Locke EA (2003). Negative self-efficacy and goal effects revisited. J Appl Psychol 88, 87.

Block CJ, Koch SM, Liberman BE, Merriweather TJ, Roberson L (2011). Contending with stereotype threat at work: a model of long-term responses. Couns Psychol 39, 570-600.

Brainard S, Carlin L (1998). A six-year longitudinal study of undergraduate women in engineering and science. J Eng Educ 87, 369-375.

Burgess DJ, Joseph A, Van Ryn M, Carnes M (2012). Does stereotype threat affect women in academic medicine? Acad Med 87, 506.

Caprara GV, Vecchione M, Alessandri G, Gerbino M, Barbaranelli C (2011). The contribution of personality traits and self-efficacy beliefs to academic achievement: a longitudinal study. Br J Educ Psychol 81, 78-96.

Carli LL, Alawa L, Lee Y, Zhao B, Kim E (2016). Stereotypes about gender and science: women $\neq$ scientists. Psychol Women Q, doi: 0361684315622645.

Carlone HB, Johnson A (2007). Understanding the science experiences of successful women of color: science identity as an analytic lens. J Res Sci Teach 44, 1187-1218.

Cooke RA, Rousseau DM (1984). Stress and strain from family roles and work-role expectations. J Appl Psychol 69, 252.

Coverman S (1989). Role overload, role conflict, and stress: addressing consequences of multiple role demands. Soc Forces 67, 965-982.

Cronan-Hillix T, Gensheimer LK, Cronan-Hillix WA, Davidson WS (1986). Students' views of mentors in psychology graduate training. Teach Psychol $13,123-127$
Diekman AB, Brown ER, Johnston AM, Clark EK (2010). Seeking congruity between goals and roles: a new look at why women opt out of science, technology, engineering, and mathematics careers. Psychol Sci 21 1051-1057.

Eccles J (1994). Understanding women's educational and occupational choices: applying the Eccles et al. model of achievement-related choices. Psychol Women Q 18, 585-609.

Eccles JS, Wigfield A (2002). Motivational beliefs, values, and goals. Annu Rev Psychol 53, 109-132.

Ellis EM (2001). The impact of race and gender on graduate school socialization, satisfaction with doctoral study, and commitment to degree completion. Western J Black Stud 25, 30-45.

Ferreira MM (2003). Gender issues related to graduate student attrition in two science departments. Int J Sci Educ 25, 969-989.

Gardner SK (2008). Fitting the mold of graduate school: a qualitative study of socialization in doctoral education. Innov High Educ 33, 125-138.

Gibbs KD, Griffin KA (2013). What do I want to be with my PhD? The roles of personal values and structural dynamics in shaping the career interests of recent biomedical science PhD graduates. CBE Life Sci Educ 12, 711-723.

Gibbs KD Jr, McGready J, Bennett JC, Griffin K (2014). Biomedical science Ph.D. career interest patterns by race/ethnicity and gender. PloS One 9 , e114736.

Good C, Rattan A, Dweck CS (2012). Why do women opt out? Sense of belonging and women's representation in mathematics. J Pers Soc Psychol $102,700-717$

Gopaul B (2011). Distinction in doctoral education: using Bourdieu's tools to assess the socialization of doctoral students. Equity Excell Educ 44, 10-21.

Hayes AF (2012). PROCESS: a versatile computational tool for observed variable mediation, moderation, and conditional process modeling (white paper). www.afhayes.com/ public/process2012.pdf (accessed 31 August 2015).

Hill C, Corbett C, St. Rose A (2010). Why So Few? Women in Science, Technology, Engineering, and Mathematics, Washington, DC: American Association of University Women. www.aauw.org/learn/research/upload/ whysofew.pdf (accessed 8 January 2016).

Hogg MA, Abrams D (1988). Social Identifications: A Social Psychology of Intergroup Relations and Group Processes, London: Routledge.

Knobloch-Westerwick S, Glynn CJ, Huge M (2013). The Matilda effect in science communication: an experiment on gender bias in publication quality perceptions and collaboration interest. Sci Commun 35, 603-625.

Lane KA, Goh JX, Driver-Linn E (2012). Implicit science stereotypes mediate the relationship between gender and academic participation. Sex Roles $66,220-234$.

Larose S, Ratelle CF, Guay F, Senécal C, Harvey M (2006). Trajectories of science self-efficacy beliefs during the college transition and academic and vocational adjustment in science and technology programs. Educ Res Eval 12, 373-393.

Lent RW, Brown SD, Hackett G (1994). Toward a unifying social cognitive theory of career and academic interest, choice, and performance. J Vocat Behav 45, 79-122.

Lent RW, Brown SD, Sheu HB, Schmidt J, Brenner BR, Gloster CS, Wilkins G, Schmidt LC, Lyons H, Treistman D (2005). Social cognitive predictors of academic interests and goals in engineering: utility for women and students at historically black universities. J Couns Psychol 52, 84

Leslie SJ, Cimpian A, Meyer M, Freeland E (2015). Expectations of brilliance underlie gender distributions across academic disciplines. Science 347 $262-265$.

London B, Rosenthal L, Levy SR, Lobel M (2011). The influences of perceived identity compatibility and social support on women in nontraditional fields during the college transition. Basic Appl Soc Psych 33 304-321.

Lovitts BE (2001). Leaving the Ivory Tower: The Causes and Consequences of Departure from Doctoral Study, Lanham, MD: Rowman and Littlefield.

Luhtanen R, Crocker J (1992). A collective self-esteem scale: self-evaluation of one's social identity. Pers Soc Psychol Bull 18, 302-318.

Maher MA, Ford ME, Thompson CM (2004). Degree progress of women doctoral students: factors that constrain, facilitate, and differentiate. Rev High Educ 27(3), 385-408. 
Major B, Spencer S, Schmader T, Wolfe C, Crocker J (1998). Coping with negative stereotypes about intellectual performance: the role of psychological disengagement. Pers Soc Psychol Bull 24, 34-50.

Marra RM, Rodgers KA, Shen D, Bogue B (2009). Women engineering students and self-efficacy: a multi-year, multi-institution study of women engineering student self-efficacy. J Eng Educ 98, 27-38.

Mattern K, Redunzel J (2015). Who Goes to Graduate School? Tracking 2003 ACT-Tested High School Graduates for More Than a Decade (ACT Research Report Series 2), lowa City, IA: ACT. www.act.org/research/ researchers/reports/pdf/ACT_RR2015-2.pdf (accessed 10 January 2016).

Mendoza-Denton R, Downey G, Purdie VJ, Davis A, Pietrzak J (2002). Sensitivity to status-based rejection: implications for African American students' college experience. J Pers Soc Psychol 83, 896.

Miller DI, Eagly AH, Linn MC (2015). Women's representation in science predicts national gender-sciences stereotypes: evidence from 66 nations. J Educ Psychol 3, 631-644.

Moss-Racusin CA, Dovidio JF, Brescoll VL, Graham MJ, Handelsman J (2012). Science faculty's subtle gender biases favor male students. Proc Natl Acad Sci USA 109, 16474-16479.

Mura R (1987). Sex-related differences in expectations of success in undergraduate mathematics. J Res Math Educ 18, 15-24.

National Academy of Sciences, National Academy of Engineering, and Institute of Medicine (2011). Expanding Underrepresented Minority Participation: America's Science and Technology Talent at the Crossroads, Washington, DC: National Academies Press.

National Institutes of Health (2012). Biomedical Research Workforce Working Group Report, Bethesda, MD.

National Science Foundation, National Center for Science and Engineering Statistics (2013). Women, Minorities, and Persons with Disabilities in Science and Engineering: 2013 (Special Report NSF 13-304), Arlington VA: National Science Foundation. www.nsf.gov/statistics/wmpd (accessed 10 January 2016).

Nelson DJ (2007). The Nelson diversity surveys. http://faculty-staff .ou.edu/N/Donna.J.Nelson-1/diversity/Faculty_Tables_FY07/ BiologyTable2007.pdf (accessed 10 January 2016).

Noe RA (1988). Women and mentoring: a review and research agenda. Acad Manage Rev 13, 65-78.

Nyquist JD, Manning L, Wulff DH, Austin AE, Sprague J, Fraser PK, Calcagno C, Woodford B (1999). On the road to becoming a professor: the graduate student experience. Change 31, 18-27.

Osborne JW (1997). Race and academic disidentification. J Educ Psychol 89, 728.

Osborne JW, Walker C (2006). Stereotype threat, identification with academics, and withdrawal from school: why the most successful students of colour might be most likely to withdraw. Educ Psychol 26, 563-577.

Pajares F (2005). Gender differences in mathematics self-efficacy beliefs. In: Gender Differences in Mathematics: An Integrative Psychological Approach, ed. AM Gallagher and JC Kaufman, New York: Cambridge University Press, 294-315.

Reuben E, Sapienza P, Zingales L (2014). How stereotypes impair women's careers in science. Proc Natl Acad Sci USA 111, 4403-4408.

Roccas S, Brewer MB (2002). Social identity complexity. Pers Soc Psychol Rev 6, 88-106.

Rosenthal L, Levy SR, London B, Lobel M, Bazile C (2013). In pursuit of the MD: the impact of role models, identity compatibility, and belonging among undergraduate women. Sex Roles 68, 464-473.

Rosenthal L, London B, Levy SR, Lobel M (2011). The roles of perceived identity compatibility and social support for women in a single-sex STEM program at a co-educational university. Sex Roles 65, 725-736.

Settles IH (2004). When multiple identities interfere: the role of identity centrality. Pers Soc Psychol Bull 30, 487-500.

Settles IH, Cortina LM, Malley J, Stewart AJ (2006). The climate for women in academic science: the good, the bad, and the changeable. Psychol Women Q 30, 47-58
Settles IH, Jellison WA, Pratt-Hyatt JS (2009). Identification with multiple social groups: the moderating role of identity change over time among women-scientists. J Res Pers 43, 856-867.

Shaw EJ, Barbuti S (2010). Patterns of Persistence in Intended College Major with a Focus on STEM Majors. NACADA J 30(2), 19-34.

Sheltzer JM, Smith JC (2014). Elite male faculty in the life sciences employ fewer women. Proc Natl Acad Sci USA 111, 10107-10112.

Shih M, Pittinsky TL, Ambady N (1999). Stereotype susceptibility: identity salience and shifts in quantitative performance. Psychol Sci 10, 80-83.

Shin JL, Levy SR, London B (2016). The effects of role model exposure on STEM and non-STEM. J Appl Soc Psychol 46, 410-427.

Smith JL, Cech E, Metz A, Huntoon M, Moyer C (2014). Giving back or giving up: Native American student experiences in science and engineering. Cult Divers Ethnic Minor Psychol 20, 413.

Smith JL, Lewis KL, Hawthorne L, Hodges SD (2013). When trying hard isn't natural: women's belonging with and motivation for male-dominated STEM fields as a function of effort expenditure concerns. Pers Soc Psychol Bull 39, 131-143.

Smith JL, Sansone C, White PH (2007). The stereotyped task engagement process: the role of interest and achievement motivation. J Educ Psychol 99, 99-114.

Smith JW, Smith WJ, Markham SE (2000). Diversity issues in mentoring academic faculty. J Career Dev 26, 251-262.

Spencer SJ, Steele CM, Quinn DM (1999). Stereotype threat and women's math performance. J Exp Soc Psychol 35, 4-28.

Steele CM (1997). A threat in the air: how stereotypes shape intellectual identity and performance. Am Psychol 52, 613.

Steele J, James JB, Barnett RC (2002). Learning in a man's world: examining the perceptions of undergraduate women in male-dominated academic areas. Psychol Women Q 26, 46-50.

Steinpreis RE, Anders KA, Ritzke D (1999). The impact of gender on the review of the curricula vitae of job applicants and tenure candidates: a national empirical study. Sex Roles 41, 509-528.

Stout JG, Dasgupta N, Hunsinger M, McManus MA (2011). STEMing the tide: using ingroup experts to inoculate women's self-concept in science, technology, engineering, and mathematics (STEM). J Pers Soc Psychol 100, 255.

Strenta AC, Elliott R, Adair R, Matier M, Scott J (1994). Choosing and leaving science in highly selective institutions. Res High Educ 35, 513-547.

Tajfel H, Turner JC (1979). An integrative theory of intergroup conflict. In: The Social Psychology of Intergroup Relations, ed. WG Austin and S Worchel, Monterey, CA: Brooks/Cole, 33-47.

Taylor E, Antony JS (2000). Stereotype threat reduction and wise schooling: towards the successful socialization of African American doctoral students in education. J Negro Educ 69, 184-198.

Thoman DB, Brown ER, Mason AZ, Harmsen AG, Smith JL (2015). The role of altruistic values in motivating underrepresented minority students for biomedicine. BioScience 65, 183-188.

Tropp LR, Wright SC (2001). Ingroup identification as the inclusion of ingroup in the self. Pers Soc Psychol Bull 27, 585-600.

U.S. Census Bureau (2014). Census Bureau Reports Majority of STEM College Graduates Do Not Work in STEM Occupations. www.census.gov/ newsroom/press-releases/2014/cb14-130.html (accessed 10 January 2016).

Walton GM, Cohen GL (2007). A question of belonging: race, social fit, and achievement. J Pers Soc Psychol 92, 82.

Wigfield A, Eccles JS (1992). The development of achievement task values: a theoretical analysis. Dev Rev 12, 265-310.

Wigfield A, Eccles JS (2000). Expectancy-value theory of achievement motivation. Contemp Educ Psychol 25, 68-81.

Woodcock A, Hernandez PR, Estrada M, Schultz P (2012). The consequences of chronic stereotype threat: domain disidentification and abandonment J Pers Soc Psychol 103, 635.

Yeager DS, Walton GM (2011). Social-psychological interventions in education: they're not magic. Rev Educ Res 81, 267-301. 